\title{
Analysis of furin ectodomain shedding in epididymal fluid of mammals: demonstration that shedding of furin occurs in vivo
}

\author{
Véronique Thimon, Maya Belghazi ${ }^{1}$, Jean-Louis Dacheux and Jean-Luc Gatti \\ Equipe 'Gamètes Males et Fertilité', UMR 6175 INRA, CNRS-Université de Tours-Haras Nationaux, Station de \\ Physiologie de la Reproduction et des Comportements, Institut National de la Recherche Agronomique, 37380 \\ Nouzilly, France and ${ }^{1}$ Service de Spectrométrie de Masse pour la Protéomique, UMR 6175 INRA, CNRS-Université de \\ Tours-Haras Nationaux, Station de Physiologie de la Reproduction et des Comportements, Institut National de la \\ Recherche Agronomique, 37380 Nouzilly, France
}

Correspondence should be addressed to J-L Gatti; Email: gatti@tours.inra.fr

V Thimon is now at Unité d'Ontogénie et Reproduction, Centre de Recherche du CHUL, 2705, Blv. Laurier, Sainte Foy, Québec, Canada G1V4G2

\begin{abstract}
Sperm cell surface proteins and proteins of their surrounding fluids are reported to be proteolytically processed in relation to acquisition of sperm fertility during epididymal transit. Several of these proteins might be potential targets for subtilisin-like proprotein convertase. Using immunochemistry and mass spectrometry analysis, we found that an $80 \mathrm{kDa}$ form of furin (EC

3.4.21.75) is present in the fluid from the mid-caput to the distal corpus regions of the epididymis of various domestic mammals. This protein is absent from the fluid of the caudal region, suggesting that it is reabsorbed or degraded. The cDNA sequence of ovine furin was obtained and the mRNA was found throughout this organ, although in greater amounts in the mid and distal caput regions. Metabolic labeling with ${ }^{35} \mathrm{~S}$-amino acids indicated that the protein was synthesized and released from the epithelium only in a restricted area of the mid-caput, suggesting a specific regionalized mechanism of secretion. The fluid protein is not pelleted at $100000 \mathrm{~g}$ and did not react with a C-terminal antibody indicating that it is not bound to membranous materials. These findings demonstrate that a furin ectodomain shedding occurs naturally in vivo in the epididymis where this enzyme could be involved in fluid and/or sperm membrane protein processing.

Reproduction (2006) 132 899-908
\end{abstract}

\section{Introduction}

The transformation of male gametes into fully motile and fertile spermatozoa is a post-testicular event that occurs in the epididymis, a long duct connecting the testis to the vas deferens and in which spermatozoa spend from days to weeks in transit (Yanagimachi et al. 1985, Jones 1998). The epididymis can be divided into three main morphological regions, i.e. the caput, the corpus, and the cauda, each region being the site of specific secretion and reabsorbtion of the duct fluid compounds by epithelial cells (Dacheux et al. 2003). The different interactions between the epididymal fluid proteins and the germinal cells are key factors in sperm maturation. Among these interactions, cell surface modifications of proteins by proteolysis and inclusion of newly synthesized and secreted proteins have been clearly demonstrated, but none of the mechanisms involved has yet been characterized (Gatti et al. 2004). However, findings have indicated that pro-protein processing can occur in the fluid and therefore specialized protease(s) involved in such activity should be present.

Furin, a calcium-dependent serine endoprotease expressed ubiquitously in mammalian tissues, is capable of processing precursors of a wide range of bioactive proteins, including some members of MMPs (matrix metalloproteinases) and surface proteins of the ADAM (a disintegrin and metalloprotease) family (for reviews: Seidah \& Chretien 1999, Seidah \& Prat 2002, Thomas 2002, Stawowy et al. 2005). This enzyme acts by endoproteolytic cleavage after the characteristic motifs containing single or paired basic amino acid residues $\mathrm{RX}(\mathrm{K} / \mathrm{R}) \mathrm{R}$ although it is able to cleave after motifs such as $(\mathrm{R} / \mathrm{K}) \mathrm{X}_{n}(\mathrm{R} / \mathrm{K}) \mathrm{R}$ (where $n$ could be $0,2,4$, or 6 amino acids) and also more degenerated motifs (Seidah \& Chretien 1999, Duckert et al. 2004). This glycoprotein is structurally composed of several domains, including a transmembrane domain and a cytoplasmic tail. The transmembrane 
domain anchors furin in the membrane of the Golgi network, but the enzyme is also localized in endosomal vesicles and at the cell surface level of different types of epithelium and endothelium (Mayer et al. 2004). It has been reported that the furin ectodomain can be found in vitro in supernatants from cell culture and this truncated form called 'shed' furin exhibits functional activity although it lacks the transmembrane domain and the cytoplasmic tail (Hatsuzawa et al. 1992, Vidricaire et al. 1993, Vey et al. 1994, Plaimauer et al. 2001, Mayer et al. 2004). However, it has not been demonstrated that an in vivo circulating form of this enzyme exists in body fluids.

This report shows that the epididymal epithelial membrane-bound furin undergoes post-translational processing that results in a soluble enzyme only in distal caput and corpus epididymal fluids of mammals. This enzyme could be a potential candidate for various modifications occurring on the sperm membrane or fluid in the distal caput-corpus region, a place where sperm acquire their ability to move and fertilize the egg.

\section{Materials and Methods}

\section{Collection of fluids and spermatozoa}

Experiments on animals were conducted according to the French laws on animal experimentation (Authorization 37-081). Epididymides and testes were removed from adult Ile de France rams (at least seven different animals), large white boars (three animals) and 'selle Français' horses (two different animals) either by castration of anesthetized animals or after slaughter. Luminal fluids were collected from the testis and different zones of the epididymis identified by numbers from 0 to 9 (caput, 0-3/4; corpus, 4-6/7; cauda, 7-9) as previously described (Edwards et al. 1976, Fouchecourt et al. 2000, Metayer et al. 2002a). Spermatozoa were separated from testicular and epididymal fluids by centrifugation (10 $\mathrm{min}, 1500 \mathrm{~g}$ ) and the supernatants were centrifuged twice at $15000 \mathbf{g}$ for $5 \mathrm{~min}$ and kept at $-20^{\circ} \mathrm{C}$. For high-speed centrifugation, $2 \mathrm{ml}$ of supernatant from zones 3 and 9 from ram and boar were submitted at $>100000 \mathrm{~g}$ for $2 \mathrm{~h}$ (rotor 50ti, L8M ultracentrifuge, 35000 r.p.m.; BeckmanCoulter, Villepinte, France), the high speed supernatant and the pellets were separated and treated for gel electrophoresis (see further).

The in vitro secretion of proteins from isolated tubules was analyzed after metabolic labeling with $100 \mu \mathrm{Ci}$ of ${ }^{35}$ S-protein labeling mix (NEN, Les Ulis, France) under $\mathrm{O}_{2}-\mathrm{CO}_{2}(95-5 \%)$ as previously described (Syntin et al. 1996). At the end of the incubation period, the luminal content of the tubule was collected and centrifuged (15 $000 \mathrm{~g}$ for $30 \mathrm{~min}$ ), and the supernatants kept at $-20^{\circ} \mathrm{C}$ until analysis by one-dimensional (1D) and twodimensional (2D) SDS-PAGE and western blotting.

\section{Gel electrophoresis and mass spectrometry}

Methods for preparing gels and samples have been previously described (Syntin et al. 1996). For non-reducing conditions, $\beta$-mercaptoethanol was omitted from sample buffer. The proteins were transferred to nitrocellulose $\left(0.8 \mathrm{~A} / \mathrm{cm}^{2}\right.$ for $\left.2 \mathrm{~h}\right)$ for immunodetection. Membranes were blocked for $1 \mathrm{~h}$ with TBS (tris buffered saline) supplemented with $0.5 \%(\mathrm{w} / \mathrm{v})$ Tween (TBST; monoclonal) and when needed $5 \%$ dried skimmed milk (polyclonals). The western blots were incubated either with the mouse MAB MON-148 (Alexis Biochemical Corp., San Diego, CA, USA) directed against the subtilisin-like catalytic domain of human furin amino acid residues 16-189 (van Duijnhoven et al. 1992) or with the rabbit polyclonal directed against the furin C-terminal peptide RGERTAFIKDQSAL (PA1-062; Affinity BioReagents, Golden, CO, USA). The antibodies were diluted in the ratio of $1: 1000$ and blots incubated $2 \mathrm{~h}$ at $37{ }^{\circ} \mathrm{C}$ or overnight at $4{ }^{\circ} \mathrm{C}$ under agitation. Blots were washed and then incubated for $1 \mathrm{~h}$ at $37^{\circ} \mathrm{C}$ with a goat anti-mouse or a goat anti-rabbit antibody conjugated with peroxidase (dilution in the ratio of 1:5000; Sigma). After washing thrice with TBST, the peroxidase was detected either on blots with 4-chloro- $\alpha$-naphthol or visualized by a digital imaging camera with a chemoluminescent substrate (as indicated).

Furin spots excised from 2D SDS-PAGE were reduced and alkylated with iodoacetamide and incubated overnight at $37^{\circ} \mathrm{C}$ in a microtube with $12.5 \mathrm{ng} / \mu \mathrm{l}$ trypsin (Sequencing grade, Sigma, France). The solution was then dried, reconstituted with $0.1 \%$ formic acid and sonicated for $10 \mathrm{~min}$. The peptides generated were sequenced by nano-LC-MS/MS (Q-TOF-Global equipped with a nanoESI source; Waters Micromass, St Quentin-en-Yvelines, France) in data-dependent acquisition mode using the three most intense parent ions. The peptides were loaded on a C18 column (Nano Ease Atlantis dC18, $3 \mu \mathrm{m} \times$ $75 \mu \mathrm{m} \times 150 \mathrm{~mm}$, Waters) and eluted with 5-60\% linear gradient at a flow rate of $180 \mathrm{nl} / \mathrm{min}$ in $30 \mathrm{~min}$ (buffer $\mathrm{A}$, water/acetonitrile 98/2 (v/v) $0.1 \%$ formic acid; buffer B, water/acetonitrile $20 / 80$ (v/v) $0.1 \%$ formic acid). MS/MS data analysis was performed with the Mascot software (www.matrixscience.com) using the NCBI non-redundant database or blasted manually against the translated sequence obtained for the ovine furin.

\section{RNA extraction and reverse transcriptase PCR (RT-PCR)}

Total RNA samples were prepared from frozen samples (200 mg) of liver, kidney, lung, heart, testis, and specified zones of the epididymis (RNAble Method, Eurobio, les Ullis, France). The reverse transcriptase assay was performed on $3 \mu \mathrm{g}$ total RNA using the Superscript Reverse transcriptase $\mathrm{H}$ (Invitrogen, Cergy Pontoise, France) and oligo(dt) primers. The epididymal furin sequence was obtained by successive PCRs with $30 \mathrm{pmol}$ of specific primers from the bovine furin precursor sequence (EMBL; European Molecular Biology Laboratory, X75956). New 
sets of primers were designed from the partial sheep sequences (A, 1-ATGCTGAGGCCTGGCCTGGTT-20; $\mathrm{A}^{\prime}$, 549-CGGGGCCATGTGTGTCTACT-569; A" , 549-GCCCCGGTACACACAGATGA-569; B， 1068-TGCGGCAGAAGTGTACAGAG-1086; B'，1257-TTTCACTCGGTAAGACCCGG-1276; C, 1310-GGCCCAGAATGGACGACAG-1330; C', 1500-GACCTTGCCATCCACCTGGT1520; D, 1629-CTCTGGCGAGTGGGTCTTAG-1648; D', 1805-CGAAGAGGAACGTGGTCTTC-1824; F, 1746CCGAGAGCATCGGCTGTAAG-1764; F', 2292-ACTTCGGACCGTCCTCCTCA-2311; G, 2283-ACTACCCCCTGAAGCCTGGC-2311; G', 2426-ACCCCGTGAAAAATTAAGTGG-2448). Complete coverage was obtained by using primer sets $A-A^{\prime}, A^{\prime \prime}-B^{\prime}, B-C^{\prime}, D-D^{\prime}, C-D^{\prime}, F-F^{\prime}$, and $\mathrm{G}-\mathrm{G}^{\prime}$ respectively. $\mathrm{PCR}$ was performed at the temperature specified for the primer set and a final elongation step at $72{ }^{\circ} \mathrm{C}$ for $5 \mathrm{~min}$. Aliquots $(5 \mu \mathrm{l})$ of each reaction mixture were analyzed on a $1.5 \%$ ethidium bromide stained agarose gel. PCRs on tissues were performed with the following pairs of primers: forward 5'-CTCTGGCGAGTGGGTCTTAG-3' and reverse 5'-CTTCTGGTGCAAGGAGAAGC-3', for either 25 or 40 cycles. $\beta$-actin primers (forward 5'-GGACTTCGAGCAGGAGATGG-3' and reverse 5'-GCACCGTGTTGGCGTAGAGG- $3^{\prime}$ ) were used as PCR controls and to equilibrate the quantity of mRNA.

\section{Northern blotting}

For each sample, $20 \mu \mathrm{g}$ total RNA were separated by electrophoresis on $1 \%$ agarose formaldehyde gel. The RNA was transferred to a nylon membrane (Hybond $\mathrm{N}+$, Amersham, Les Ulis, France) by overnight capillary blotting in $20 \times$ SSC and cross-linked by exposure for $30 \mathrm{~s}$ under u.v. light. The membrane was stored at room temperature until pre-hybridization. A cDNA probe for furin was made by RT-PCR from zone 3 and labeled with ${ }^{32}$ P-dCTP (Megaprime II, Amersham). Hybridization was performed overnight at $42{ }^{\circ} \mathrm{C}$ with a membrane prehybridized with $100 \mu \mathrm{g} / \mathrm{ml}$ salmon sperm DNA ( $2 \mathrm{~h}$ at $42{ }^{\circ} \mathrm{C}$ ). After incubation, the membrane was then washed once in $1 \times$ SSC $-0.5 \%$ SDS (20 min at room temperature) and then thrice in $0.2 \times \mathrm{SSC}-0.5 \% \mathrm{SDS}\left(20 \mathrm{~min}\right.$ at $\left.68^{\circ} \mathrm{C}\right)$. The transcript was visualized after exposure on radioactivity-sensitive screen or film.

\section{Protein deglycosylation}

Fluid from zones $3 / 4$ was boiled in the presence of $1 \%(\mathrm{v} / \mathrm{v})$ $\beta$-mercaptoethanol, and $0.2 \%(\mathrm{w} / \mathrm{v})$ SDS for $5 \mathrm{~min}$ and then incubated for $2 \mathrm{~h}$ at $37{ }^{\circ} \mathrm{C}$ in the presence of $2 \%(\mathrm{w} / \mathrm{v})$ CHAPS (3-[(3-Cholamidopropyl)dimethylammonio]-1propanesulfonate), $5 \mathrm{mM}$ EDTA, and $5 \cup \mathrm{N}$-glycosidase $\mathrm{F}$ (Roche) for $2 \mathrm{~h}$ at $37^{\circ} \mathrm{C}$. Negative controls were prepared by replacing the $\mathrm{N}$-glycosidase $\mathrm{F}$ by an equal volume of $\mathrm{H}_{2} \mathrm{O}$. The reaction was stopped by heating the sample for 5 min at $95^{\circ} \mathrm{C}$.

\section{Results}

\section{Immunodetection of furin in mammalian epididymal fluids}

Equivalent amounts of fluid proteins obtained from the rete testis and different epididymal zones (0-9) from rams, boars, and stallions were separated by SDS-PAGE and transferred to nitrocellulose. The membrane probed with the anti-furin MAB showed the presence of one strong reactive band at about $80 \mathrm{kDa}$ in the distal caput and corpus fluids in all three species (Fig. 1). This immunoreactive protein was absent in the proximal caput and cauda, except in the stallions where faint reactivity could be detected. A less intense immunoreaction could be also detected in zones $1 / 2$ in some rams but never in the testis, efferent duct, or zones $0 / 1$. We also extracted the proteins from ovine sperm obtained from the same zones, but when probed with the antifurin antibody these extracts did not show any reactive band (not shown), indicating that the fluid furin did not derive from sperm.

Ram epididymal fluid from zone 3 was further separated by 2D electrophoresis and one gel was blotted, probed with anti-furin antibody, and revealed with 4-chloro- $\alpha$-naphthol before staining with Ponceau red (Fig. 2A). Several reactive spots with pl around 6.5-7 were found, suggesting that the protein is post-translationally modified. A similar gel was stained with Coomassie brilliant blue and the equivalent spots to those immunoreactive on western blot were localized (Fig. 2B, arrows). Porcine and equine epididymal fluids from zone 3 were treated the same way (data not shown). All these matching spots from the different species were excised from the gel and treated for analysis by mass
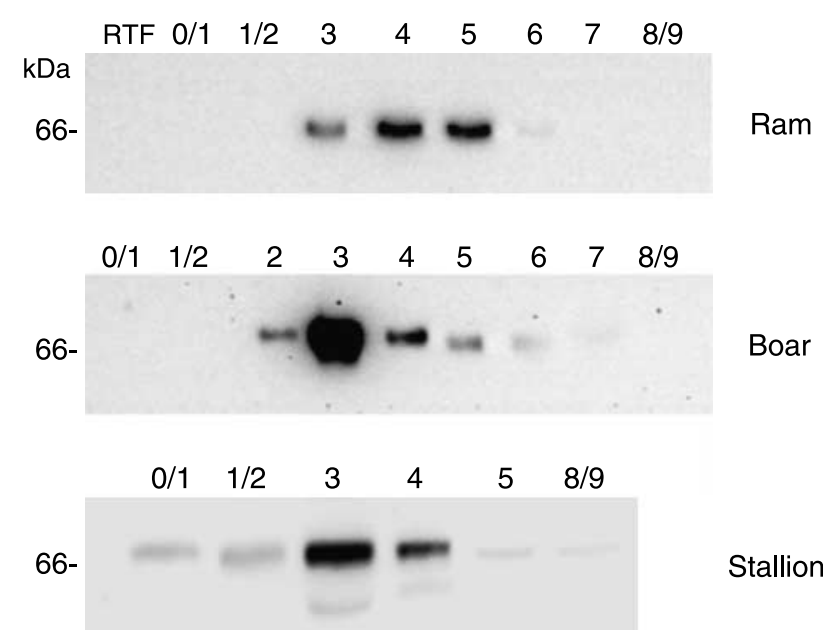

Figure $1 \mathrm{Imm}$ modetection of furin in mammalian epididymal fluids. Equivalent amounts of proteins from ram, boar, and horse rete testis fluid, and epididymal fluids (zones 0 to $8 / 9$ ) were loaded on a $6-16 \%$ SDS-PAGE, blotted, and probed with anti-furin MAB. A strong immunoreaction at about $70 \mathrm{kDa}$ was observed from the mid caput and corpus regions in all three species. 

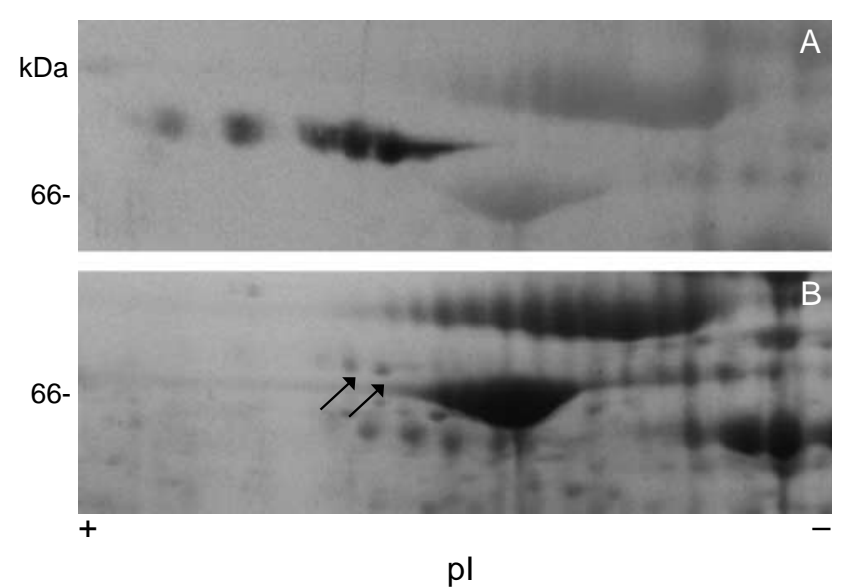

Figure 2 2D SDS-PAGE separation of furin. Ram epididymal fluid from zone 3 (about $100 \mu$ g protein) was separated by 2D electrophoresis. One gel was transferred and probed with the anti-furin antibody revealed by 4 -chloro- $\alpha$-naphthol and then stained with Ponceau red (A). The matching spots (arrows) found on an equivalent Coomassie blue stained gel (B) were excised from the gel to be treated for mass spectrometry analysis (see Table 1).

spectrometry. The sequence obtained from the tryptic fragments by LC-MS-MS confirmed that the spots in the three species were furin (Table 1).

\section{Sequence and tissue expression of ram furin}

We determined the complete cDNA sequence of ovine furin by successive PCRs (Fig. 3; EMBL acc no. AM084381). The derived 794 amino acid sequence (theoretical Mw: 86898 ; pl 6.06) showed up to $97 \%$ identity with the bovine furin sequence and more than $90 \%$ identity to the other mammalian (human, rat, mouse) furin sequences available on the database.

This sequence presented the canonical regions of furin as four furin-like repeats including two cysteine-rich regions (regions 586-618 and 643-675), the peptidase region (129-301) including the classical triad Asp-HisSer forming the active center (149, 194, and 366 respectively) and the p-domain specific of the eukaryotic subtilisin-like pro-protein convertases (444-574) (Seidah \& Chretien 1999, Thomas 2002).

From this sheep sequence, specific primers were designed and used to study furin expression. Furin amplicon was found as expected in the kidneys, heart, lungs, and liver, although the amounts of messenger were variable even after 40 PCR cycles (Fig. 4A). The messenger was present in the testes and the different parts of the epididymis, as shown after 40 cycles of PCR, although at a lower number of cycles (25) differences in quantity were visible, with preferential expression in the caput (Fig. 4B). The difference was further confirmed by northern blotting (Fig. 4C). Using the amplicon from zone 3 as a probe, a $>4 \mathrm{~kb}$ radioactive band was observed in the different zones but radioactivity was
Table 1 LC-MS-MS sequences obtained for the Ram, Boar and Stallion epididymal furin.

\begin{tabular}{ll}
\hline Species & Peptide sequences \\
\hline Ram & LTLSYNR \\
& CVIDILTEPK \\
& DMQHLVVR \\
& GIVVSILDDGIEK \\
& MLDGEVTDAVEAR \\
& FPQQWYLSGVTQR \\
& TVDGPAHLAEEAFFR \\
& TLTSSQACVVCEEGFSLHQK \\
& LTLSYNR \\
& QIVTTDLR \\
& GIVVSILDDGIEK \\
& CIIDILTEPKDIGKR \\
& MLDGEVTDAVEAR \\
& GGLGSIFVWASGNGGR \\
& TVTACLGEPSHITR \\
& LAEEAFFRGVSQGR \\
& RGDLAIHLVSPMGTR \\
& KTVTACLGEPSHITR \\
& DLNVKEAWAQGYTGR \\
& TLTSSQACVVCEEGFSLHQK \\
& TVTACLGEPSHITRLEHAQAR \\
& FTLVLYTAPEGLPTPPESIGCK \\
& KTVTACLGEPSHITRLEHAQAR \\
& NHPDLAGNYDPGASFDVNDQDPDPQPR \\
& SLGLNPNHIHIYSASWGPEDDGKTVDGPAR \\
& LTLSYNR \\
& QIVTTDLR \\
& GIVVSILDDGIEK \\
& MLDGEVTDAVEAR \\
& MLDGEVTDAVEAR \\
& GGLGSIFVWASGNGGR \\
& TLTSSACVVCEEGFSLHQK \\
& TVTACLGEPSHITRLEHAQAR \\
& GIVVSILDDGIEKNHPDLAGNYDPGASFDVN...DQDPDPQPR \\
Stallion & \\
& \\
& \\
& \\
&
\end{tabular}

Sequences of peptides were obtained by homology with bovine furin precursor (Q28193), rat furin precursor (P23377), and human furin precursor (P09958) and the sheep sequence from Fig. 3.

much higher in zones 2-4 although the same quantities of mRNA were used as shown by the $28 \mathrm{~S}$ and $18 \mathrm{~S} \mathrm{mRNA}$ staining in the different gel lanes (Fig. 4C, bottom).

\section{Epithelial cell-derived epididymal fluid furin}

Furin mRNA was present throughout the epididymal zones, although in different amounts, but the protein was visible only in the distal caput and corpus. We then investigated whether this protein was secreted in the different zones or in a more restricted area. Isolated tubules from the different zones were incubated in the presence of ${ }^{35} \mathrm{~S}$-methionine and cysteine, and after $6 \mathrm{~h}$ the luminal fluid was perfused and separated by 1D and 2D gel (Syntin et al. 1996). The 1D SDS-PAGE probed with the anti-furin antibody indicated that the protein was present from zones 2 to 6 in this animal (data not shown). Two gels were then prepared for each immunoreactive zone. One gel was silver stained and the second was blotted and revealed with 
ATG GAG CTG AGG CCC TGG TTG TTC TGG GTG GTA GCA ATA GCG GGA GCC TTG ATT CTG CTG GTG GCC GAT GCC CGC GGA GAG AAG $\begin{array}{llllllllllllllllllllllllllll}\text { M } & \text { E } & \text { L } & \text { R } & \text { P } & \text { W } & \text { L } & \text { F } & \text { W } & \text { V } & \text { V } & \text { A } & \text { I } & \text { A } & \text { G } & \text { A } & \text { L } & \text { I } & \text { L } & \text { L } & \text { V } & \text { A } & \text { D } & \text { A } & \text { R } & \text { G } & \text { E } & \text { K }\end{array}$

GTC TTC ACC AAC ACC TGG GCC GTG CAC ATT CCT GGA GGC CCA GCC GTC GCT GAC CGT GTG GCG CAC AAG CAT GGC TTC CTC AAC

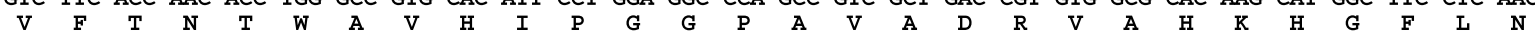
CTG GGC CAG ATC TTC GGT GAC TAT TAC CAC TTC TGG CAT CG GCG GTG ACA AAG CGG TCC CTG TCG CCT CAC CTC CCG CGG CAC

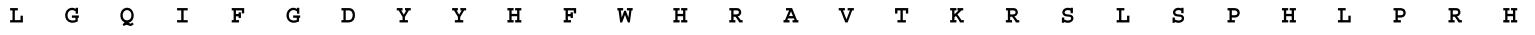

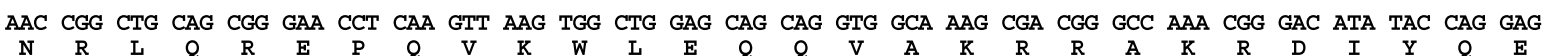
CCC ACG GAC CCC AAg TTT CCC CAG CAG TGG TAC CTG TCT GGT GTC ACC CAG CGg GAC CTG AAT GTG AAG GAG GCC TGG GGC CAG $\begin{array}{llllllllllllllllllllllllllll}\mathrm{P} & \mathrm{T} & \mathrm{D} & \mathrm{P} & \mathrm{K} & \mathrm{F} & \mathrm{P} & \mathrm{Q} & \mathrm{Q} & \mathrm{W} & \mathrm{Y} & \mathrm{L} & \mathrm{S} & \mathrm{G} & \mathrm{V} & \mathrm{T} & \mathrm{Q} & \mathrm{R} & \mathrm{D} & \mathrm{L} & \mathrm{N} & \mathrm{V} & \mathrm{K} & \mathrm{E} & \mathrm{A} & \mathrm{W} & \mathrm{G} & \mathrm{Q}\end{array}$ GGC TAC ACG GGG CGC GGC ATT GTG GTC TCT ATC CTG GAT GAC GGC ATC GAG AAG AAC CTC CCC GTC TTG GCA GGC AAT TAT GAT CCT GGG GCC AGC TTC GAT GTC AAT GAT CAG GAC CCT GAC CCC CAG CCC CGG GTC ACA CAG ATG AAT GAC AAC AGG CAT GGC ACA CGG TGT GCA GGA GAG GTG GCT GCN GTG GCC AAC AAT GGT GTC TGT GGT GTA GGC GTG GCC TAC AAT GCC CGC ATT GGA GGG GTG

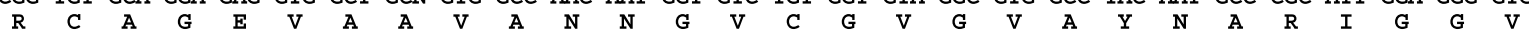
CGC ATG CTG GAC GGC GAA GTG ACA GAC GCC GTG GAG GCA CGC TCG CTG GGC CTG AAC CCC AAC CAC ATC CAC ATC TAC AGT GCC

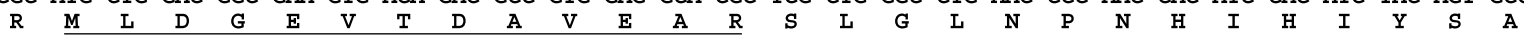
AGC TGG GGC CCC GAG GAC GAC GGC AAG ACC GTG GAT GGG CCA GCC CAC CTG GCT GAG GAG GCC TTC TTC CGG GGG GTC AGC CAG

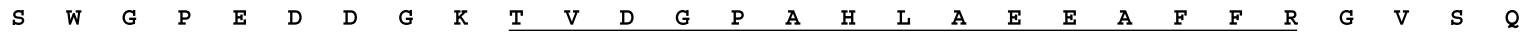
GGC CGT GGG GGT CTG GGC TCC ATC TTT GTC TGG GCC TCG GGG AAC GGG GGC CGG GAA CAT GAC AGC TGC AAT TGC GAC GGC TAC ACC AAC AGC ATC TAC ACG CTG TCC ATC AGC AGC GCC ACA CAG TTC GGC AAC GTG CCC TGG TAC AGT GAG GCC TGC TCG TCC ACA

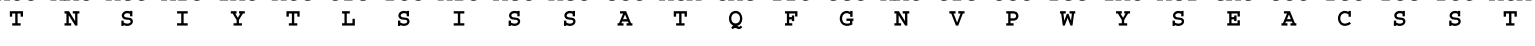

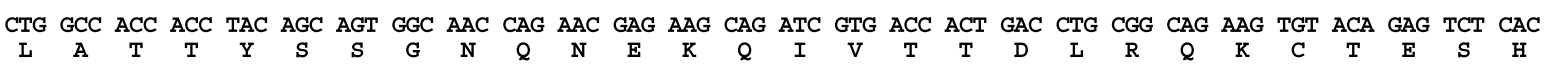
ACG GGC ACC TCT GCG TCT GCC CCC CTG GCA GCA GGC ATC ATT GCT CTC ACC CTG GAG GCC AAT AAG AAC CTC ACC TGG CGG GAC

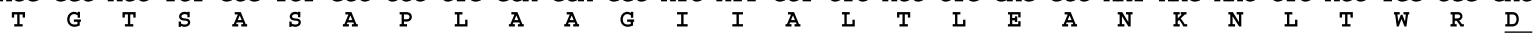
ATG CAG CAC TTG GTG GTC CGG ACC TCA AAG CCA GCC CAC CTC AAC GCC AAC GAC TGG GCC ACC AAC GGT GTG GGC CGC AAA GTG

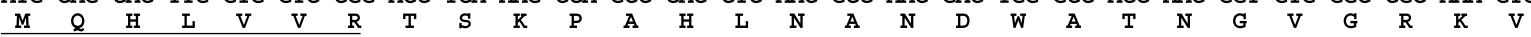
AGC CAT TCG TAC GGC TAT GGG CTG TTG GAC GCC GGC GCC ATG GTG GCT CTG GCC CAG AAT TGG ACG ACA GTG GCC CCT CAG CGG

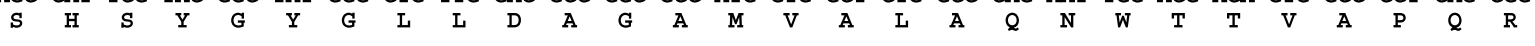

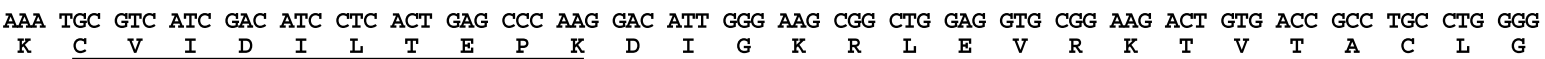
CAG CCC AGC CAC ATC ACG CGG CTG GAG CAC GCT CAG GCG CGG CTC ACC CTG TCC TAC AAC CGC CGC GGT GAC CTT GCC ATC CAC

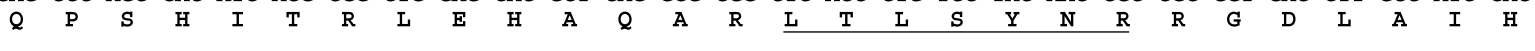

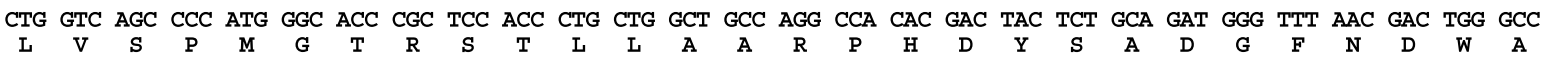
TTC ATG ACG ACC CAT TCC TGG GAC GAG GAT CCC TCT GGC GAG TGG GTC TTA GAG ATT GAA AAC ACC AGT GAA GCC AAA AAC TAT

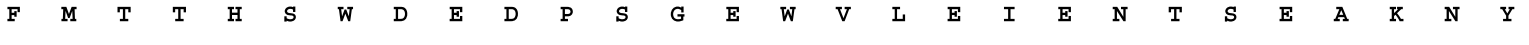

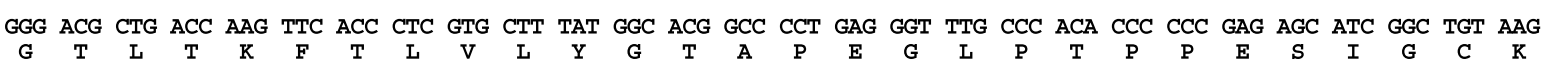
ACC CTC ACT TCC AGC CAG GCC TGT GTG GTG TGC GAG GAA GGC TTC TCC TTG CAC CAG AAG AAC TGC GTC CAG CAC TGT CCC CCA

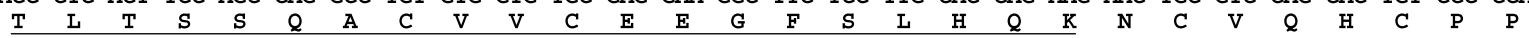
GGC TTC GCT CCC CAA GTC CTG GAC ACA CAC TAC AGC ACA GAG AAC GAC GTG GAG ATC ATC CGG GCC AGC GTC TGC ACG CCC TGC

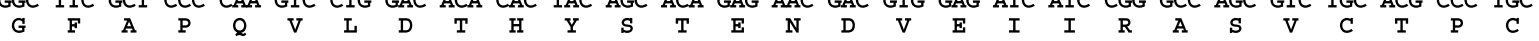
CAC ACC TCG TGC GCC ACG TGC CAG GGC CCC GCC CCC ACA GAC TGC CTC AGC TGC CCC AGC CAC GCC TCC CTG GAC CTC GTG GAG 2016

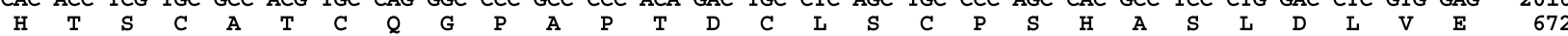
CGG ACG TGC TCG CGC CAG AGC CAG AGC AGC CGC GAG TCG CAC CAG CAG CAG CCG CCA CCG CCG CCG CCC GTG GAG GTG GCG TCG 2100 $\begin{array}{lllllllllllllllllllllllllllll}R & T & C & S & R & Q & S & Q & S & S & R & E & S & H & Q & Q & Q & P & P & P & P & P & P & V & E & V & A & S & 700\end{array}$ GAG CCG CGG CTG CGG GCG GAC CTG CTG CCC TCG CAC CTG CCC GAG GTG GTG GCC GGC CTC AGC TGC GCC TTC ATT GTG CTG GTC 2184 $\begin{array}{llllllllllllllllllllllllllllllll}\text { E } & \text { P } & \text { R } & \text { L } & \text { R } & \text { A } & \text { D } & \text { L } & \text { L } & \text { P } & \text { S } & \text { H } & \text { L } & \text { P } & \text { E } & \text { V } & \text { V } & \text { A } & \text { G } & \text { L } & \text { S } & \text { C } & \text { A } & \text { F } & \text { I } & \text { V } & \text { L } & \text { V } & 728 & \end{array}$ TTC GTC ACC GTC TTC CTG GTC CTG CAG CTG CGC TCG GGC TTC AGC TTC CGA GGG GTG AAA GTG TAC ACC ATG GAC CGT GGC CTC 2268

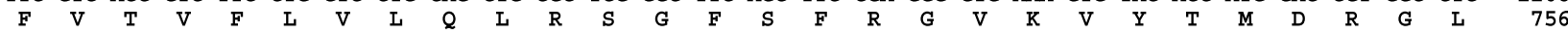

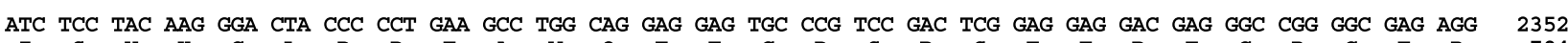

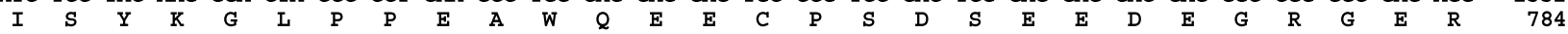

ACC GCC TTT ATC AAA GAC CAG AGC GCC CTT 2382

$\begin{array}{lllllllllllll}\text { T } & \text { A } & \text { F } & \text { I } & \text { K } & \text { D } & Q & \text { S } & \text { A } & \text { L } & 794\end{array}$

Figure 3 Sheep furin cDNA sequence. Nucleotide and predicted amino acid sequences of the cDNA that encodes sheep furin (EMBL acc no. AM084381). The underlined sequences are those obtained by LC-MS-MS from the ram epididymal fluid furin. 

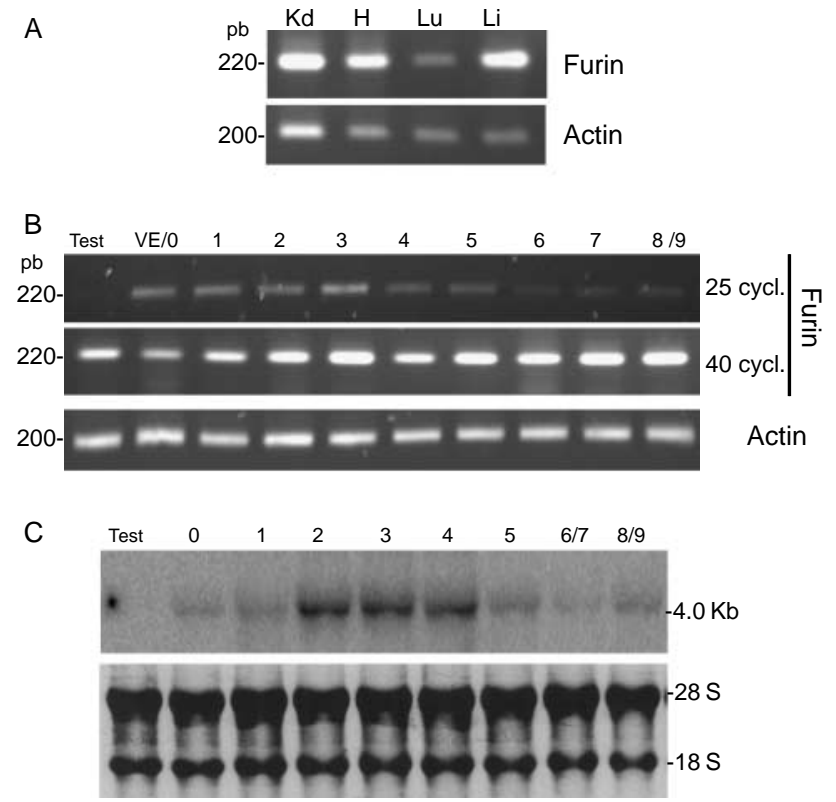

Figure 4 Tissue expression of furin mRNA. (A) Complementary cDNA obtained after 40 PCR cycles for furin in the Kidneys $(\mathrm{Kd})$, Heart $(\mathrm{H})$, Lung (Lu), and Liver (Li). Actin PCR (25 cycles) showed the related amounts of cDNA in the different samples. (B) Furin mRNA was also amplified by 40 PCR cycles using CDNA prepared from the testis and the different epididymal zones. When only 25 cycles were used, furin amplicon was not observed in the testis and was less amplified in the cauda than in the caput and corpus. Actin PCR ( 25 cycles) was used to equilibrate cDNA of the different tissues. (C) Total RNA samples from the testis and different epididymal zones were hybridized with a cDNA furin probe, a transcript was observed in all epididymal zones but quantities were greater in zones 2 to $4.18 \mathrm{~S}$ and $28 \mathrm{~S}$ mRNAs were used to visualize mRNA quantities from the gel. $\mathrm{pB}$, bp.

the anti-furin antibody, then both the gel and the membrane were dried and exposed to autoradiographic films (Fig. 5). The furin immonoreactive spots were found by immunoblotting from zones 2 to 6 and these spots could be matched with radioactive spots only from zones 2 to 4 (Fig. 5). Immunoreactive spots could be seen in zone 2, but the radioactive and silver stain spots were barely visible, indicating a low level of secretion and accumulation (Fig. 5, Z2 arrows). In zones 3 and 4, the secreted spots were well individualized and could be easily matched with the strong immunoreactive and silver stained spots (Fig. $5 \mathrm{Z3}$ and Z4 boxes). The secretion was lower in zone 4 than in zone 3 . In zone 6 , the protein was still present in the fluid, as shown both by silver staining and immunoblotting, but no ${ }^{35}$ S-labeled protein could be seen (Fig. 5, Z6), suggesting that it is only weakly secreted and that the immunoreactive protein was a remnant from secretion of the previous zones transported by the fluid.

\section{The fluid furin is a shed domain truncated C-terminally}

Since furin is normally an intravesicular protein that could be found at the cell surface and as it is known that vesicular systems are present in the epididymal fluid of

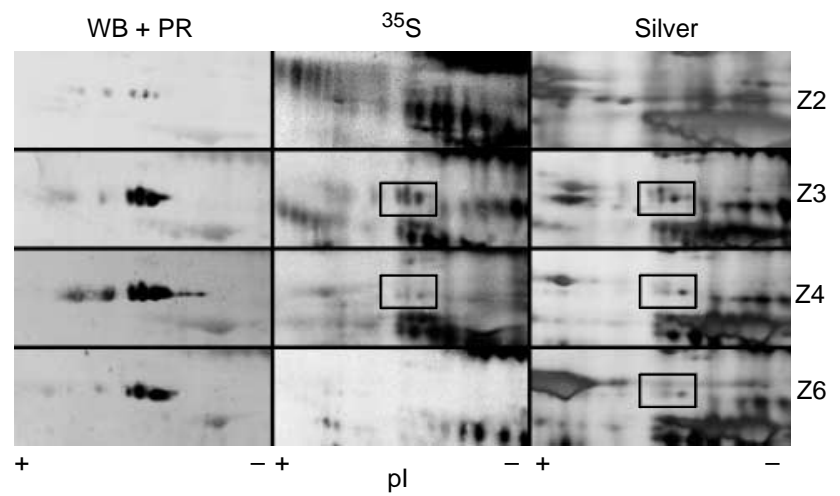

Figure 5 Analysis of furin secretion. Ram epididymal fluid from was obtained from Z2 to Z6 after metabolic labeling of the tubule secretion by ${ }^{35} \mathrm{~S}$-cysteine and methionine. Equivalent amounts of fluid proteins from each zone were separated by 2D gel electrophoresis. One gel was transferred and probed with the anti-furin antibody, revealed by 4-chloro- $\alpha$-naphthol and then stained with Ponceau red (WB + PR). The strong dark spots indicated the furin position. This blot was dried and the radioactive proteins revealed by autoradiography $\left({ }^{35} \mathrm{~S}\right)$ to match the immunoreactive spots with the secretions (boxes). An equivalent gel was silver stained (silver) to visualize the proteins present in the fluid and match the furin spots with the immunoreactive and radioactive spots (boxes).

mammals (Dacheux et al. 2005, Gatti et al. 2005), it was important to determine whether the fluid furin was attached to membrane or secretion vesicles or free in the fluid as a shed extracellular domain. The fluid from zones 3 and 9 from ram and boar were high-speed centrifuged at $>100000 \mathrm{~g}$ for $2 \mathrm{~h}$ in order to pellet all membranous materials and vesicles. Visible pellets were found in cauda fluids of both species and in zone 3 fluid of boar but not of ram. The supernatant of each samples and the resuspended pellet (or the solution used for washing the bottom of the tube of zone 3 from ram) were loaded on gels, transferred to nitrocellulose and probed with the monoclonal MON-148 or the anti-C-terminal polyclonal (Fig. 6). For both ram and boar the $>100000 \mathrm{~g}$ centrifugation did not change the immunoreactivity of the fluid at $80 \mathrm{kDa}$ and only low reactivity was found in the pellet (note that the pellet is concentrated 25 times for ram and 5 times for boar from the initial volume). In boar, a $43 \mathrm{kDa}$ reactive band became visible in the pellet that was only barely visible in the fluid. No clear reactive band could be found in the cauda fluid and pellets from ram and boar (data not shown). When similar blots were probed with the polyclonal antibody against the C-terminal only a low intensity band could be observed at 50-55 kDa in ram fluid but not in pellet, while in boar only immunoreactive bands at about $14 \mathrm{kDa}$ could be observed in the fluid and at $43 \mathrm{kDa}$ in the pellet. Only the $14 \mathrm{kDa}$ bands were clearly visible in boar cauda fluids before and after high-speed centrifugation but not in pellet, and no other bands could be observed (data not shown). 

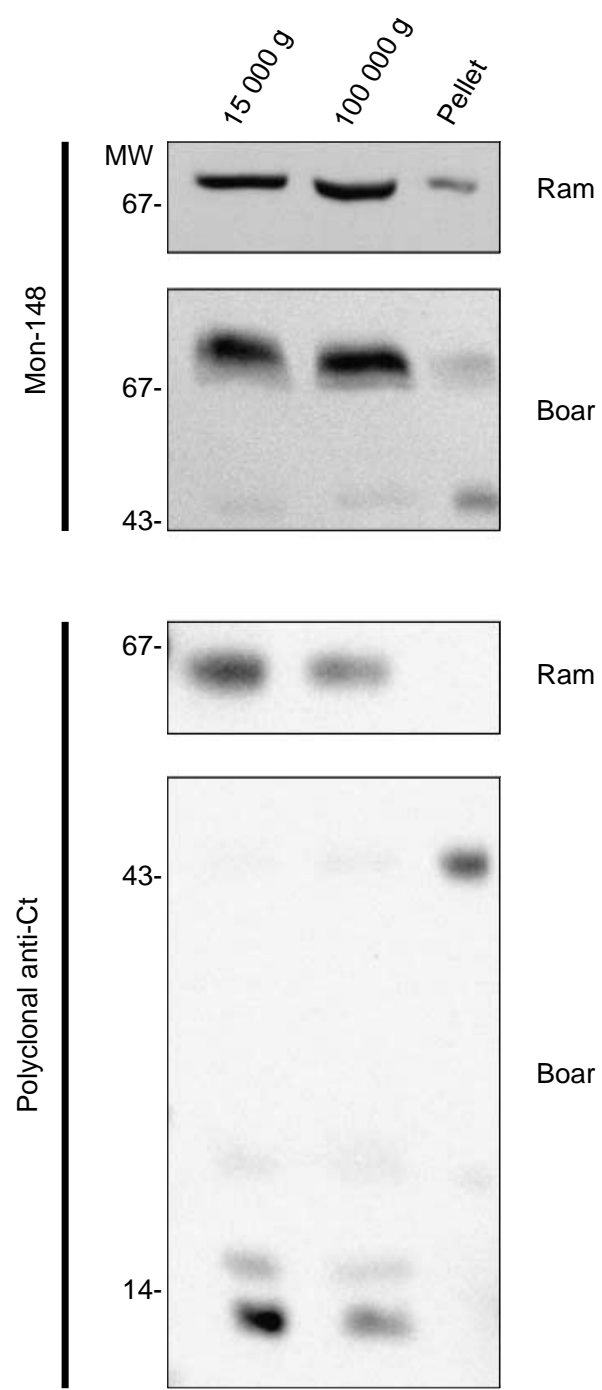

Ram

Boar

Figure 6 The furin ectodomain is shed and C-terminally truncated. Fluid from epididymal zone 3 of ram and boar $(2 \mathrm{ml}$ pooled from three different animals for both species) were centrifuged at $15000 \boldsymbol{g}$ then at $100000 \mathrm{~g}$ for $2 \mathrm{~h}$. The supernatants labeled 15000 and $100000 \mathrm{~g}$ respectively as well the pellet or the material collected from the bottom of the tube (labeled pellet) were separated on a $6-16 \%$ SDS-PAGE, transferred onto nitrocellulose, and probed either with the mouse monoclonal 148 (Mon-148) or the rabbit polyclonal anti C-terminal (polyclonal anti-Ct). The secondary peroxidase antibody was revealed with 4-chloro- $\alpha$-naphthol and the blot photographed for the Mon-148 and imaged with a digital device using a sensitive chemoluminescent substrate for the rabbit polyclonal.

\section{Shed furin domain is monomeric and $\mathrm{N}$-glycosylated}

Fluids from zones $3 / 4$ were run on mono-dimensional gel under non-reducing or reducing conditions in order to ascertain the size of the shed domain (Fig. 7). In the presence or the absence of $\beta$-mercaptoethanol, the protein migrated at the same apparent molecular weight, suggesting that it is monomeric and no part of the prodomain remains linked by disulfide bonds to the shed ectodomain. It has been shown that furin is a
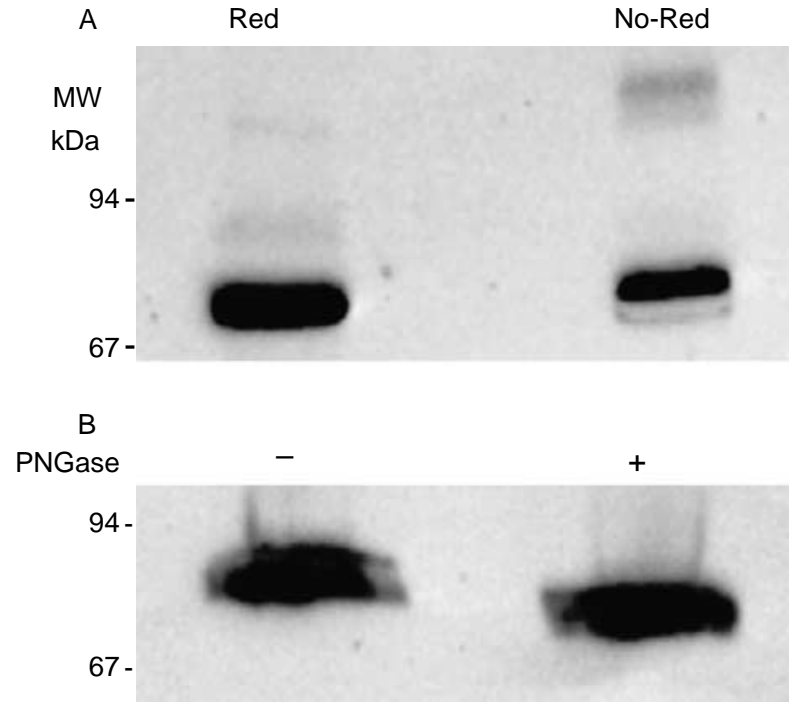

Figure 7 The shed furin ectodomain is monomeric and glycosylated. Ram epididymal fluid from zones 3 to 4 was run under reducing (Red) or non-reducing (NoRed) conditions and the nitrocellulose probed with the MAB Mon-148. No important difference in migration was observed. (B) The same fluid was run under reducing conditions with (+) or without (-) treatment with PNGase $\mathrm{F}$ in order to remove the $\mathrm{N}$ glycosylation. The treatment resulted in a molecular weight shift of about $7-10 \mathrm{kDa}$ as calculated from the standard molecular weight migration.

$\mathrm{N}$-glycosylated protein, when the fluid from regions 3/4 was treated with $\mathrm{N}$-glycosidase (PNGase $\mathrm{F}$ ), a shift of about $7-10 \mathrm{kDa}$ on the apparent $\mathrm{MW}$ of furin was observed showing the presence of $\mathrm{N}$-glycosylation and indicating that the shed domain amino acid sequence is about $70 \mathrm{kDa}$ in mass.

\section{Discussion}

Furin (EC3.4.21.75, also called PACE or paired basic amino acid residue-cleaving enzyme) is an endoprotease that belongs to the family of mammalian subtilisin-like pro-protein convertases. This family comprises nine members subdivided into three classes according to their tissue distribution. For example, furin, PACE4, PC5/PC6, and PC7/PC8 are widely distributed in the body tissues, PC1/PC3 and PC2 are mostly in neuroendocrine tissues, while PC4 is a mammalian testicular enzyme (for reviews: Steiner 1998, Seidah \& Chretien 1999, Bergeron et al. 2000, Taylor et al. 2003). PCs are processing enzymes that act to mature a wide variety of proteins, such as hormones, growth factors, proteases, bacterial toxins, and virion coat glycoproteins, by cleaving their pro-domains (Chretien et al. 1995, Denault \& Leduc 1996, Nakayama 1997). These different enzymes may have a certain level of redundancy but may also have specific functions in certain organs (Roebroek et al. 2004). Furin mRNA has previously been found in the testis (Torii et al. 1993) but not, to our knowledge, 
reported in the epididymal tissue where it is present throughout this organ but with different levels of expression according to the region. We also clearly demonstrated by immunoblotting and mass spectrometry that this protease is transiently present in the luminal fluid of the mammalian epididymis, as the result of shedding after synthesis by the epithelium occurring in a very restricted area comprising the mid- and distal caput.

Furin shares its common mosaic structure with the other family members: i.e. a signal peptide, a pro-domain, a catalytic domain, a ' $\mathrm{P}$ ' domain, and a carboxyl-terminal domain that anchors the protein in membrane. The sequence obtained for the sheep furin was in complete agreement with this description. In general, the catalytic domain is the most conserved sequence among the subtilisin-like proteases while the C-terminal domain is less conserved, although it plays an important role in the intracellular routing of the enzyme (Seidah \& Chretien 1999, Thomas 2002). For example, the furin cytoplasmic tail contains phosphorylation sites and their level of phosphorylation allows the protein to pass from the Golgi to the plasma membrane via the secretory granules and then to return to the Golgi via the endocytotic pathway. The presence of furin at the cell surface during this cycle has been documented and its involvement in cell surface modifications of proteins demonstrated (Steiner 1998, Mayer et al. 2004, Koo et al. 2006). Several studies using different in vitro cell systems overexpressing this enzyme have reported the existence of truncated forms of furin in culture medium as a result of a proteolytic process (Vidricaire et al. 1993, Vey et al. 1994, Plaimauer et al. 2001). Furin is normally synthesized in a zymogenic form as a $100 \mathrm{kDa}$ precursor and is activated and sorted after an intramolecular autoproteolytic cleavage of its pro-peptide, leaving a $90 \mathrm{kDa}$ protein in cells (Creemers et al. 1995). Once released in the culture medium, the mature active ectodomain was found at $75-80 \mathrm{kDa}$, in agreement with an initial site of cleavage after $\mathrm{Arg}^{683}$ leaving a 10-15 kDa tail in the cell (Plaimauer et al. 2001). The presence of only one mRNA transcript in the epididymis indicates that the mature protein must be at least $90 \mathrm{kDa}$ (from the translated cDNA sequence) without the mass of post-translational processing such as glycosylation and sialylation (Hatsuzawa et al. 1992). The fluid protein is about $80 \mathrm{kDa}$ under denaturing and non-denaturing conditions and $\mathrm{N}$-glycosylations represent $7-10 \mathrm{kDa}$ of this mass. Thus the final difference in mass observed of about $20 \mathrm{kDa}$ fits quite well with the removal of the transmembrane and intracellular domains and strongly suggests that the extracellular domain is released in the fluid upon a proteolytic shedding. This conclusion is also sustained by our different results which showed that the $80 \mathrm{kDa}$ fluid furin is (i) not bound to membraneous materials, (ii) not reactive with the anti-C-terminal polyclonal antibody, and (iii) none of the peptides obtained by mass spectrometry in the three species are situated within the $\mathrm{N}$-terminal or C-terminal part of the enzyme.
In boar, we observed that a 14 and $18 \mathrm{kDa}$ immunoreactive $\mathrm{C}$-terminal are present in the fluid and accumulate in the cauda, but this immunoreactive compounds are not linked to vesicles or membranes. This compounds may be secreted within membraneous apical blebs that are rapidly destroyed after their secretion in the fluid (Hermo \& Jacks 2002, Dacheux et al. 2005). It has not yet been clearly established whether the $\mathrm{C}$-terminal cleavage of furin occurs intracellularly, leading to the secretion of the truncated form, or whether it occurs once the mature protein is on the cell surface. In the former case, it is suggested that furin itself or a related PC is involved in this process (Denault et al.2002), although the cleavage site is not a canonical sequence for these enzymes. Moreover, the fact that mutation or deletion of the cleavage site severely reduces ectodomain release without suppressing it suggests that there is no definite cleavage site (Plaimauer et al. 2001). Alternatively, this might indicate that different enzymes could be involved in the ectodomain shedding process, such as the described membrane metalloproteases, from the ADAM family (TACE (tumor necrosis factor-alpha-converting enzyme), ADAM10, ADAM9, etc.) or an unknown serine protease (Pang et al. 2001). Interestingly, several ADAMs (ADAM7, ADAM28, etc.) are expressed in an epididymal regionspecific manner (caput region) and the activation of these proteases may require the action of furin or other PCs (Howard et al. 2000, Oh et al. 2005) and may in turn play a role in the shedding of these proteins.

Shedding of furin in the epididymis occurs in a region where several proteins from the sperm surface and from their surrounding media are processed. For example, we have shown that the germinal form of angiotensin-I converting enzyme (ACE) located at the sperm surface is removed from these cells as they pass through the anterior caput epididymis. We recently reported that this release is dependent upon a serine protease activity that is present in or activated by the fluid from this area (Gatti et al. 1999, Metayer et al. 2002b, Thimon et al. 2005). The shedding of germinal ACE (gACE) and furin thus occurs at very close sites in the epididymis after a similar proteolytic cleavage after an Arg situated at about 25-30 amino acids from the transmembrane domain. Serine protease activity has also been reported to be involved in the processing of sperm surface proteins such as fertilin and some other ADAM proteins (Frayne et al. 1998, Blobel 2000, 2005) and hyaluronidase 2B1-pH20 (Jones et al. 1996, Morin et al. 2005). These proteins have been shown to be processed when sperm cross the caput or corpus epididymis and to be involved in sperm fertility. We have also reported that several members of the matrix metalloproteases present in the epididymal fluid were activated from pro- to active forms after their transformation within the fluid (Metayer et al. 2002a), and it has recently been demonstrated that an anti-microbial protein in human epididymal fluid and seminal plasma is processed in vivo and in vitro by furin (von Horsten et al. 2002). 
We investigated the enzymatic activity of the shed furin in the fluid with a specific fluorogenic substrate (Angliker et al. 1995). Although the activity measured in the crude epididymal fluids was very sensitive to the reported furin peptidyl inhibitor (decanoyl-Arg-Val-LysArg-chloromethylketone), we observed that the substrate was also cleaved by other peptidyl proteases present in the fluid such as ACE, neprilysin, and dipeptidylpeptidase IV (Gatti et al. 2005, Thimon 2005). Classical chromatographic purification could not provide evidence that the fluid furin was active since furin could not be completely separated ACE (Thimon 2005). Moreover, the epididymal fluid is known to contain a large number of protease inhibitors (including PC2 cystatin-like inhibitor; Cornwall et al. 2003), which may also interfere with this type of measurement.

The role of furin on sperm fertility remains to be clearly established. Unfortunately, furin-knockout (KO) mice are not viable and cannot be used to evaluate the role of furin in fertility, and this would require a mouse model with a conditional $\mathrm{KO}$ in the epididymis.

In conclusion, we have provided the first demonstration that a furin-shed ectodomain is present in a body fluid, the epididymal fluid of mammals, where it might be involved in maturation of diverse pro-proteins present on sperm and in the fluid. The epididymis, which is a closed environment, represents an interesting model to study the extracellular activity of such shed ectodomain but also to study the shedding mechanism, which may also occur in other organs but may be more difficult to study in vivo.

\section{Acknowledgements}

The authors would like to thank Dr T Moreau (INSERM EMI-U 00-10, University François Rabelais, Tours) for valuable discussions and help in setting up enzyme activity measurements and Dr Joelle Dupont for advice on molecular biology techniques. We would also like to thank Ms V Labas for her help in mass spectrometry and Mr Guillaume Tsikis for his technical assistance. The authors gratefully acknowledge the help of the staff at the experimental facilities of the PRC. The Region Centre and a grant from GIS-GENANIMAL supported this study. The authors declare that there is no conflict of interest that would prejudice the impartiality of this scientific work.

\section{References}

Angliker H, Neumann U, Molloy SS \& Thomas G 1995 Internally quenched fluorogenic substrate for furin. Analytical Biochemistry 224 409-412.

Bergeron F, Leduc R \& Day R 2000 Subtilase-like pro-protein convertases: from molecular specificity to therapeutic applications. Journal of Molecular Endocrinology 24 1-22.

Blobel CP 2000 Functional processing of fertilin: evidence for a critical role of proteolysis in sperm maturation and activation. Reviews of Reproduction 5 75-83.

Blobel C 2005 ADAMS: key component in EGFR signalling and development. Nature Reviews. Molecular Cell Biology 6 33-43.
Chretien M, Mbikay M, Gaspar L \& Seidah NG 1995 Proprotein convertases and the pathophysiology of human diseases: prospective considerations. Proceedings of the Association of American Physicians 107 47-66.

Cornwall GA, Cameron A, Lindberg I, Hardy DM, Cormier N \& Hsia N 2003 The cystatin-related epididymal spermatogenic protein inhibits the serine protease prohormone convertase 2. Endocrinology 144 901-908.

Creemers JW, Vey M, Schafer W, Ayoubi TA, Roebroek AJ, Klenk HD, Garten W \& Van de Ven WJ 1995 Endoproteolytic cleavage of its propeptide is a prerequisite for efficient transport of furin out of the endoplasmic reticulum. Journal of Biological Chemistry $\mathbf{2 7 0}$ 2695-2702.

Dacheux JL, Gatti JL \& Dacheux F 2003 Contribution of epididymal secretory proteins for spermatozoa maturation. Microscopy Research and Technique 61 7-17.

Dacheux JL, Castella S, Gatti JL \& Dacheux F 2005 Epididymal cell secretory activities and the role of proteins in boar sperm maturation. Theriogenology 63 319-341.

Denault JB \& Leduc R 1996 Furin/PACE/SPC1: a convertase involved in exocytic and endocytic processing of precursor proteins. FEBS Letters 379 113-116.

Denault J, Bissonnette L, Longpre J, Charest G, Lavigne P \& Leduc R 2002 Ectodomain shedding of furin: kinetics and role of the cysteinerich region. FEBS Letters 527 309-314.

Duckert P, Brunak S \& Blom N 2004 Prediction of proprotein convertase cleavage sites. Protein Engineering, Design \& Selection 17 107-112.

Edwards EM, Dacheux JL \& Waites GM 1976 Effects of alphachlorohydrin on the metabolism of testicular and epididymal spermatozoa of rams. Journal of Reproduction and Fertility $\mathbf{4 8}$ $265-270$

Fouchecourt S, Metayer S, Locatelli A, Dacheux F \& Dacheux JL 2000 Stallion epididymal fluid proteome: qualitative and quantitative characterization; secretion and dynamic changes of major proteins. Biology of Reproduction 62 1790-1803.

Frayne J, Jury JA, Barker HL \& Hall L 1998 The MDC family of proteins and their processing during epididymal transit. Journal of Reproduction and Fertility. Supplement 53 149-155.

Gatti JL, Druart X, Guerin Y, Dacheux F \& Dacheux JL 1999 A 105- to 94-kilodalton protein in the epididymal fluids of domestic mammals is angiotensin I-converting enzyme (ACE); evidence that sperm are the source of this ACE. Biology of Reproduction 60 937-945.

Gatti JL, Castella S, Dacheux F, Ecroyd H, Metayer S, Thimon V \& Dacheux JL 2004 Post-testicular sperm environment and fertility. Animal Reproduction Science 82-83 321-339.

Gatti JL, Metayer S, Belghazi M, Dacheux F \& Dacheux JL 2005 Identification, proteomic profiling, and origin of ram epididymal fluid exosome-like vesicles. Biology of Reproduction 72 1452-1465.

Hatsuzawa K, Nagahama M, Takahashi S, Takada K, Murakami K \& Nakayama K 1992 Purification and characterization of furin, a Kex2like processing endoprotease, produced in Chinese hamster ovary cells. Journal of Biological Chemistry 267 16094-16099.

Hermo L \& Jacks D 2002 Nature's ingenuity: bypassing the classical secretory route via apocrine secretion. Molecular Reproduction and Development 63 394-410.

Howard L, Maciewicz RA \& Blobel CP 2000 Cloning and characterization of ADAM28: evidence for autocatalytic pro-domain removal and for cell surface localization of mature ADAM28. Biochemical Journal 348 21-27.

Jones RC 1998 Evolution of the vertebrate epididymis. Journal of Reproduction and Fertility. Supplement 53 163-181.

Jones R, Ma A, Hou ST, Shalgi R \& Hall L 1996 Testicular biosynthesis and epididymal endoproteolytic processing of rat sperm surface antigen 2B1. Journal of Cell Science 109 2561-2570.

Koo BH, Longpre JM, Somerville RP, Alexander JP, Leduc R \& Apte SS 2006 Cell-surface processing of Pro-ADAMTS9 by Furin. Journal of Biological Chemistry 281 12485-12494. 
Mayer G, Boileau G \& Bendayan M 2004 Sorting of furin in polarized epithelial and endothelial cells: expression beyond the Golgi apparatus. Journal of Histochemistry and Cytochemistry $\mathbf{5 2}$ 567-579.

Metayer S, Dacheux F, Dacheux JL \& Gatti JL 2002a Comparison, characterization, and identification of proteases and protease inhibitors in epididymal fluids of domestic mammals. Matrix metalloproteinases are major fluid gelatinases. Biology of Reproduction 66 1219-1229.

Metayer S, Dacheux F, Dacheux JL \& Gatti JL 2002b Germinal angiotensin I-converting enzyme is totally shed from the rodent sperm membrane during epididymal maturation. Biology of Reproduction 67 1763-1767.

Morin G, Lalancette C, Sullivan R \& Leclerc P 2005 Identification of the bull sperm p80 protein as a $\mathrm{PH}-20$ ortholog and its modification during the epididymal transit. Molecular Reproduction and Development 71 523-534.

Nakayama K 1997 Furin: a mammalian subtilisin/Kex2p-like endoprotease involved in processing of a wide variety of precursor proteins. Biochemical Journal 327 625-635.

Oh J, Woo JM, Choi E, Kim T, Cho BN, Park ZY, Kim YC, Kim do H \& Cho C 2005 Molecular, biochemical, and cellular characterization of epididymal ADAMs, ADAM7 and ADAM28. Biochemical and Biophysical Research Communications 331 1374-1383.

Pang S, Chubb AJ, Schwager SL, Ehlers MR, Sturrock ED \& Hooper NM 2001 Roles of the juxtamembrane and extracellular domains of angiotensin-converting enzyme in ectodomain shedding. Biochemical Journal 358 185-192.

Plaimauer B, Mohr G, Wernhart W, Himmelspach M, Dorner F \& Schlokat U 2001 'Shed' furin: mapping of the cleavage determinants and identification of its C-terminus. Biochemical Journal 354 689-695.

Roebroek AJ, Taylor NA, Louagie E, Pauli I, Smeijers L, Snellinx A, Lauwers A, Van de Ven WJ, Hartmann D \& Creemers JW 2004 Limited redundancy of the proprotein convertase furin in mouse liver. Journal of Biological Chemistry 279 53442-53450.

Seidah NG \& Chretien M 1999 Proprotein and prohormone convertases: a family of subtilases generating diverse bioactive polypeptides. Brain Research 848 45-62.

Seidah NG \& Prat A 2002 Precursor convertases in the secretory pathway, cytosol and extracellular milieu. Essays in Biochemistry 38 79-94.

Stawowy $P$, Meyborg $H$, Stibenz D, Stawowy NB, Roser $M$, Thanabalasingam U, Veinot JP, Chretien M, Seidah NG, Fleck E, et al. 2005 Furin-like proprotein convertases are central regulators of the membrane type matrix metalloproteinase-pro-matrix metalloproteinase-2 proteolytic cascade in atherosclerosis. Circulation 111 2820-2827.
Steiner DF 1998 The proprotein convertases. Current Opinion in Chemical Biology 2 31-39.

Syntin P, Dacheux F, Druart X, Gatti JL, Okamura N \& Dacheux JL 1996 Characterization and identification of proteins secreted in the various regions of the adult boar epididymis. Biology of Reproduction $\mathbf{5 5}$ 956-974.

Taylor NA, Van De Ven WJ \& Creemers JW 2003 Curbing activation: proprotein convertases in homeostasis and pathology. FASEB Journal 17 1215-1227.

Thimon V 2005 Protéases et maturation épididymaire des spermatozoïdes. PhD Thesis. Université de Tours.

Thimon V, Metayer S, Belghazi M, Dacheux F, Dacheux JL \& Gatti JL 2005 Shedding of the germinal angiotensin-I converting enzyme (gACE) involves a serine protease and is activated by epididymal fluid. Biology of Reproduction 73 881-890.

Thomas G 2002 Furin at the cutting edge: from protein traffic to embryogenesis and disease. Nature Reviews. Molecular Cell Biology $3753-766$.

Torii S, Yamagishi T, Murakami K \& Nakayama K 1993 Localization of Kex2-like processing endoproteases, furin and PC4, within mouse testis by in situ hybridization. FEBS Letters 316 12-16.

van Duijnhoven HL, Creemers JW, Kranenborg MG, Timmer ED, Groeneveld A, van den Ouweland AM, Roebroek AJ \& van de Ven WJ 1992 Development and characterization of a panel of monoclonal antibodies against the novel subtilisin-like proprotein processing enzyme furin. Hybridoma 11 71-86.

Vey M, Schafer W, Berghofer S, Klenk HD \& Garten W 1994 Maturation of the trans-Golgi network protease furin: compartmentalization of propeptide removal, substrate cleavage, and $\mathrm{COOH}$ terminal truncation. Journal of Cell Biology 127 1829-1842.

Vidricaire G, Denault JB \& Leduc R 1993 Characterization of a secreted form of human furin endoprotease. Biochemical and Biophysical Research Communications 195 1011-1018.

von Horsten HH, Derr P \& Kirchhoff C 2002 Novel antimicrobial peptide of human epididymal duct origin. Biology of Reproduction 67 804-813.

Yanagimachi R, Kamiguchi Y, Mikamo K, Suzuki F \& Yanagimachi H 1985 Maturation of spermatozoa in the epididymis of the Chinese hamster. American Journal of Anatomy 172 317-330.

Received 22 June 2006

First decision 28 July 2006

Accepted 23 August 2006 